\title{
Desenho de pesquisa, inferência e causalidade: \\ caminhos entre a abordagem qualitativa e quantitativa
}

ISSN: 2236-451X

\author{
Rodrigo Leite \\ Doutorando, Universidade Federal de Pernambuco - UFPE \\ Gustavo de Andrade Rocha \\ Doutorando, Universidade Federal de Pernambuco - UFPE
}

\begin{abstract}
O presente trabalho pretende abordar três questões fundamentais no âmbito da pesquisa em ciência política: o desenho de pesquisa, a inferência e a causalidade. Para tanto, discorrerá essas questões estabelecendo os paralelos de cada uma entre as abordagens qualitativa e quantitativa. Como resultado, estabelecerá que, apesar do método quantitativo ter sua cientificidade mais aceita, ante o uso de técnicas estatísticas, os métodos qualitativos possuem também elementos e técnicas próprias que podem contribuir para a elaboração de inferências causais. Aliado a este fator, as pesquisas que se utilizam dos dois métodos para o teste de hipóteses podem ser também um grande aliado da ciência política e corroboram os novos estudos da área que tentam mitigar a antiga dicotomia entre as técnicas quantitativas e qualitativas.
\end{abstract}

Palavras-chave: Ciência Política; Metodologia; Qualitativa; Quantitativa.

\section{INTRODUÇÃO}

O trabalho ora apresentado trata de discorrer sobre duas questões fundamentais na pesquisa em ciência política: o desenho de pesquisa e a causalidade. Como complemento, esses três pontos chaves serão discutidos sob a perspectiva dos métodos qualitativos e quantitativos.

A obra elaborada por King, Keohane e Verba (1994) tratou de estabelecer que para existir uma cientificidade no âmbito da pesquisa social, deveria haver uma lógica única de inferência, baseada em técnicas de cunho quantitativo. Assim, as abordagens qualitativas somente teriam validade com o rigor estatístico.

As críticas à orientação defendida por King, Keohane e Verba (1994) foram diversas, sendo uma das principais, a coletânea de textos organizada por Brady e Collier (2004), que tentam mitigar esta dicotomia quantitativa/qualitativa e defender que os mé- 
todos quantitativos podem também se valer de postulados qualitativos, assim como estes últimos possuem elementos e características próprias que justificam técnicas que se afastam do uso de operações puramente matemáticas. Em específico, no texto que corresponde ao primeiro capítulo do texto (BRADY, COLLIER e SEAWRIGHT, 2004), começam a discussão sobre a hegemonia quantitativa e apresentam a tradição qualitativa como sendo tão "científica" quanto sua tradição irmã.

Assim, o que o texto pretende responder é se de fato, a inferência e a causalidade podem ser realizadas sob a ótica qualitativa, sem o uso de elementos quantitativos. $\mathrm{E}$ se justifica este questionamento, posto que os postulados defendidos por King, Keohane e Verba (1994) foram durante muito tempo tidos como a obra seminal no campo da metodologia da pesquisa aplicada à ciência política.

No entanto, este trabalho pretende ir mais além e aborda ainda novas orientações no campo da metodologia, que à parte da discussão entre os métodos qualitativos e quantitativos, procuram contribuir com a ciência política ao defender técnicas de pesquisa que podem se utilizar dos dois métodos tradicionais. Dessa forma, os três elementos chaves que serão estudados - o desenho de pesquisa, a inferência e a causalidade - deverão se amoldar à técnica que melhor se adeque ao objeto de estudo e ao problema da pesquisa.

Para tanto, este texto será dividido em três etapas, a primeira sobre o desenho de pesquisa, a segunda sobre as inferências nas ciências sociais e por fim, a terceira etapa sobre as relações causais. Após isso, serão apresentadas algumas breves considerações finais.

\section{O DESENHO DE PESQUISA}

$\mathrm{O}$ ato concreto de pesquisar inicia-se com o desenho de pesquisa. Trata-se, em termos gerais, de delinear os passos que serão dados pelo investigador para a condução da análise do seu objeto de pesquisa.

Sobre este tema, King, Keohane e Verba (1994) definem que uma pesquisa deve ter quatro características: a) ter como objeto a extração de inferências descritivas ou explicativas; b) utilizar-se de métodos explícitos, codificados e públicos; c) deve alcançar-se resultados incertos, ou seja, deve haver um cálculo das incertezas; e d) a pesquisa deve centrar-se no método, que é o seu principal conteúdo.

Os autores também relatam que as ciências sociais pretendem explicar uma realidade social complexa. E uma das formas de compreender estes fatos é a busca de generalizações, que conceituam cada caso dentro de um tipo de acontecimentos. Dos quais, procura-se estabelecer quais são suas características gerais

No entanto, as diretrizes iniciais estabelecidas pelo pesquisador não devem ser estáticas. Seguidores desta orientação, King, Keohane e Verba (1994) defendem que um bom cientista social deve ser suficientemente flexível para revisar o desenho de pesquisa apropriadamente e coletar dados diferentes do que havia pensado no início. Para 
isso, devem-se seguir procedimentos explícitos que respeitem as normas de inferência.

Em complementação, discutem quais seriam os principais componentes do desenho de pesquisa, ou seja, que fatores devem ser lapidados e aprofundados. Os autores, então, apontam quatro: a) a melhora das perguntas de pesquisa; b) o aprimoramento da teoria; c) a qualidade dos dados; e d) utilizar melhor os dados existentes.

Sobre a pergunta de pesquisa, os autores afirmam que não há um método lógico para se obter ideias, e nem tão pouco as razões pessoais são necessárias ou suficientes para justificar a escolha de um tema. Assim, propõem que, em primeiro lugar, um projeto de pesquisa tem que suscitar uma pergunta importante, relevante, para o mundo real. Em segundo lugar, a pergunta deve fazer uma "contribuição" concreta aos escritos da área acadêmica. Nesse sentido, o pesquisador deve situar o desenho de pesquisa dentro do marco da bibliografia científica existente, pois tal fato garantirá que o pesquisador compreende o estado da arte e reduz ao mínimo a possibilidade de repetir o que já foi realizado.

Em relação ao melhoramento da teoria ${ }^{1}$, King, Keohane e Verba (1994) defendem que ao estudar as teorias já existentes, deve-se, em primeiro lugar, eleger aquelas que estão equivocadas, em segundo, deve-se escolher uma teoria que possa gerar consequências observáveis, e por fim, ao elaborar teorias, faz-se necessário ser o mais concreto possível.

Quanto às diretrizes para melhorar a qualidade dos dados, os autores defendem que se deve inicialmente registrar e detalhar o processo que gerou os dados. Para meIhor avaliar uma teoria, deve-se também obter dados acerca da maior quantidade possível de consequências observáveis. Outras diretrizes seriam maximizar a validez das medições, assegurar-se que os métodos de coleta de dados são confiáveis, e por fim, que todos os dados e análises feitas devem ser, na medida do possível, reproduzíveis.

Para melhor utilizar os dados, o pesquisador deve, sempre que possível, fazer inferências utilizando dados que não sejam tendenciosos, ou seja, que estejam corretos. A segunda diretriz se baseia no conceito estatístico de eficiência, e consiste em maximizar a informação que se tomou em consideração para fazer inferências descritivas ou causais.

A preocupação em elaborar um bom desenho de pesquisa também se fez presente no estudo de Filho et al (2012), que tratou de apresentar dez procedimentos para auxiliar o pesquisador a melhorar a qualidade do seu desenho final de pesquisa. Estas propostas foram elaboradas com base no referencial teórico existente e na experiência dos autores em ensino e pesquisa. As sugestões foram divididas em dois grupos: (a) substantivas e (b) procedimentais. As sugestões substantivas foram as seguintes: (1) explicitar e justificar a questão de pesquisa; (2) descrever os métodos e as técnicas; (3) simplificar a hipótese de trabalho; (4) produzir inferências causais falsificáveis; e (5) apresentar as limitações do desenho de pesquisa. Por sua vez, as propostas de cunho procedimentais são: (6) minimizar a complexidade da linguagem; (7) compartilhar a base

${ }^{1}$ Entende-se que é o conhecimento sistematizado, fundamentado através da filosofia e de observações empíricas, que visa uma aproximação com a realidade para explicá-la e compreendê-la. 
de dados; (8) evitar gráficos nebulosos e tabelas poluídas e incompletas; (9) ser criticado antes de publicar e (10) escolher adequadamente os meios de divulgação.

Interessante notar que este estudo é bastante completo, abarcando desde os procedimentos iniciais da pesquisa, como a sua justificativa, até as preocupações após a conclusão, como o ato de buscar espaços onde a pesquisa possa ser analisada e criticada, e até a escolha do meio de divulgação.

Estas questões referidas nos parágrafos anteriores podem ser aplicadas no âmbito da pesquisa em ciência política de forma geral. Observe-se, no entanto, que cada técnica metodológica irá constituir um desenho de pesquisa específico. E dessa forma, é aconselhável que o pesquisador tenha o conhecimento amplo do objeto de pesquisa para a adequação prévia do método ao objeto. No estudo de caso, por exemplo, Borges (2007, p. 57) aponta que a técnica de Process Tracing ${ }^{2}$ tem inúmeras vantagens, mas algumas limitações. Uma delas, é que a sua adequação se dá de melhor forma quando há uma "cadeia causal ininterrupta para justificar a sua utilização", sendo que outros tipos de processo causal são mais adequados à análise estatística multivariada.

Outro exemplo, é a pesquisa política comparada³. Explica Pérez-Liñán (2010, p. 126) que o método comparativo requer uma série de decisões prévias referentes ao desenho de pesquisa. Landman (2011, p. 50), por sua vez, esclarece que a distinção entre os diferentes métodos comparados deveria considerar-se em função da pergunta de pesquisa, do tempo e dos recursos do pesquisador, do método que se sente mais cômodo, assim como da posição epistemológica que adote. No entanto, apesar dessas questões práticas serem relevantes, o autor afirma que a distinção central (e a escoIha a ser feita) entre os métodos comparativos tem ligação com o nível de abstração e o número de países objeto do estudo, pois em geral, quanto mais elevado o nível de abstração conceitual, haverá mais margem para incluir um maior número de países na comparação. Dessa forma, três seriam os métodos de comparação em relação ao nível de abstração e o número de países: a comparação de muitos países, de poucos países, e o estudo de um único estado.

Profundamente relacionado com o desenho de pesquisa, está a discussão sobre qual o método mais adequado à ciência política: o qualitativo ou quantitativo. A obra de King, Keohane e Verba (1994) tratou profundamente da questão e referenciou que deveria existir uma lógica inferencial única para ambos os métodos, baseada mais em critérios quantitativos. Em comentário a esta obra, Rezende (2011, p. 224) explica que para aqueles autores, os desenhos de pesquisa devem atender a dois critérios: por um lado, os "cientistas devem ter considerável atenção com o tratamento de questões relevantes para o mundo empírico, e, por outro lado, devem se voltar essencialmente para garantir a produção de explicações científicas dos fenômenos políticos".

\footnotetext{
${ }^{2}$ Em português, "Mapeamento de Processos", os autores George e Bennet (2005 apud Borges, 2007) definem como o procedimento de identificação dos processos causais intervenientes entre uma variável dependente e uma ou mais variáveis independentes.

${ }^{3}$ Política Comparada é o subcampo da Ciência Política que se ocupa da comparação de casos. Este subcampo desenvolveu um ferramental de pesquisa próprio, denominada metodologia política comparada neste trabalho, em outras palavras, a metodologia da política comparada.
} 
Rezende (2011, p. 224) assim complementa que para King, Keohane e Verba (1994), enquanto os problemas e questões empíricas relevantes na ciência política são abundantes, a produção científica com a utilização de inferências causais ainda são raras, especialmente nas pesquisas qualitativas. E dessa forma, "o problema crucial da ciência política como ciência reside, portanto, na sua carência metodológica para que se possa testar hipóteses e gerar teorias”. Assim, a solução ao problema dada por estes autores é a utilização de técnicas qualitativas com pressupostos e desenhos de pesquisa quantitativas, especialmente a realização de inferências causais.

Não obstante, a riqueza e profundidade da solução apontada por King, Keohane e Verba (1994), que é o ponto de partida deste debate, diversas críticas foram elaboradas à obra, como por exemplo, os textos reunidos na obra de Brady e Collier (2004). Rezende, por sua vez, foi também bastante enfático ao afirmar que existem três condições em que os métodos quantitativos "não se prestam adequadamente para produzir inferências causais na ciência política" (2011, p. 228). O primeiro deles seria a diferenciação que existe entre os propósitos fundamentais entre abordagens da pesquisa histórico-comparada e da análise multivariada. A segunda questão reside no problema da singularidade dos fenômenos estudados pela ciência política, onde não é possível se supor uma lógica quantitativa de análise, "dado que se está diante de fenômenos raros, únicos, que pouco tem a ver com a análise de regularidades ou de padrões normais para que se possa compreender causalidade e produzir inferências causais" (REZENDE, 2011, p. 228).

A terceira consideração tem relação com a natureza específica da explicação política, que depende fortemente presença de agências e das instituições. Dessa forma, as análises que tentam inserir a agência e as instituições terminam por se voltar para desenhos de pesquisa que privilegiam a "atenção para processos causais, contextos, contingencias, escolhas, interações, e outros elementos que são melhor capturados por desenhos de pesquisa qualitativos" (REZENDE, 2011, p. 229).

\section{A INFERÊNCIA}

O processo de inferência na ciência política é, muito provavelmente, um dos elementos mais sensíveis com que um pesquisador tem de lidar. Trata-se, em termos muito simples, de extrair dos dados, informações e correlações, associados com a teoria, uma interpretação com significância para a teoria e para a ciência política. Como se trata de uma interpretação do pesquisador, nem toda pesquisa precisa fazer inferência. A pesquisa pode ser descritiva, exploratória ou mesmo associativa ${ }^{4}$. Porém, a inferência atribui à pesquisa o caráter de inovação, de contribuir para a qualidade da teoria.

Essa sensibilidade se dá em face da ciência política se tratar de uma ciência social, e portanto, trabalhar apenas com aproximações da realidade. Além disso, por mais que haja um esforço para melhorar a qualidade do levantamento de informações, os dados e as variáveis sempre serão imperfeitos. E na melhor das hipóteses, as inferên-

\footnotetext{
${ }^{4}$ É claro, existem outras classificações.
} 
cias serão feitas com base em dados de momentos, e frequentemente, com amostras. Levantar dados de todo o universo analisado nem sempre é possível. Mesmo quando é possível realizar um censo do objeto analisado, a precisão dos dados frequentemente é questionável.

Essas ressalvas, extraídas de obras como a de Przeworsky e Tenue (1970), King, Keohane e Verba (1994) e Brady e Collier (2004), frequentemente, e em diversos contextos, mencionam essas dificuldades.

Em "Designing Social Inquiry", King, Keohane e Verba (1994) constroem um conceito de inferência científica nas ciências sociais. Esse conceito, segundo seus autores, é aplicável para ambas as tradições da pesquisa social (eles referem-se à pesquisa qualitativa e quantitativa). Segundo a construção feita pelos autores, seguindo seus preceitos de inferência, as ciências sociais conseguiriam consolidar seu caráter como ciência.

A principal contribuição desta obra de King, Keohane e Verba, na realidade, é a construção de um primeiro conceito de inferência científica nas ciências sociais, e do estabelecimento de padrões para que esta inferência seja considerada científica. O ponto de partida dos autores é a tradição quantitativa, e desta perspectiva, projetam os pressupostos do arcabouço quantitativo como referência para a pesquisa social, independente da natureza da pesquisa. Apesar das várias críticas, algumas delas legítimas, os próprios críticos entendem que a contribuição de sua obra é fundamental para o avanço da ciência política.

Mesmo que Brady e Collier (2004) tenham questionado a perspectiva do livro de King, Keohane e Verba (1994), sem entrar no mérito da justiça ou da consistência de seus argumentos, eles não questionam em nenhum momento a necessidade de haver preceitos científicos para as inferências nas ciências sociais. Entretanto, os artigos reunidos por Brady e Collier, de maneira geral, manifestam a perspectiva de que a tradição qualitativa teria mais a contribuir com o conceito de inferência do que King, Keohane e Verba (1994) deixam transparecer em sua obra.

Em específico, os capítulos da seção "Criticas do Modelo Quantitativo" (BRADY, 2004; BARTELS, 2004; ROGOWSKY, 2004) da obra de Brady e Collier (2004) criticam a perspectiva adotada por King, Keohane e Verba (1994) de adotar os parâmetros da tradição quantitativa para a inferência. Alegam que a tradição qualitativa tem sua contribuição para construção de uma inferência científica. Mesmo não apresentando objetivamente nestes capítulos quais são esses parâmetros, a suposição pode ser considerada válida. Porém, não há um argumento que desmereça a contribuição da obra seminal de King, Keohane e Verba (1994). Em outras palavras, reconhecem sua contribuição, mas chamam a atenção para outras possibilidades de desenhos de pesquisa, com outros pressupostos, desde que mantida a solidez metodológica.

$\mathrm{Na}$ tentativa de apresentar perspectivas de cada tópico, serão apresentados a seguir o que seria um conceito geral de inferência extraído das três obras, e dois conceitos ampliados, partindo deste primeiro conceito, buscando levar em consideração as discussões das duas tradições (qualitativa e quantitativa). Mas antes, é preciso ressaltar que as linhas de pesquisa não são herméticas entre si, portanto, podem ser combina- 
das em pesquisas nas ciências sociais. Essa talvez seja a maior lição apresentada pela coletânea de Brady e Collier (2004), de que é possível combinar métodos quantitativos e qualitativos sem ter uma receita pré-determinada de como fazer, possibilitando um conjunto maior de inovação nos métodos a serem empregados.

Ao retomar a discussão sobre o conceito de inferência, pode-se defini-la de maneira genérica como a extração de explicações e conclusões através dos dados coletados e analisados de maneira consistente de acordo com o arcabouço metodológico vigente, levando em consideração o que afirma a teoria.

Apesar do conceito de inferência não sofrer variação nas abordagens qualitativas e quantitativas, as perspectivas sobre a sua implementação difere um pouco. Em linhas gerais, para a tradição quantitativa, uma inferência científica válida é aquela feita a partir da cuidadosa análise de dados, de um universo estatisticamente significante, calculados cuidadosamente. Portanto, para fundamentar uma inferência científica, é necessário ter um resultado confiável, é necessário seguir os preceitos da estatística aplicada, e tomar cuidado com o cálculo das variáveis. Nesse caso, os desenhos de pesquisa tentam aproximar, através da estatística, da inclusão de controles, da realidade de uma pesquisa experimental.

Do ponto de vista da pesquisa qualitativa, para que uma inferência seja consistente, é necessário ter informações suficientes e confiáveis, que permitam fundamentá-la. Nesse caso, a inferência está ligada diretamente aos dados qualitativos levantados. Esta pesquisa tende a buscar explicação de consequências de casos individuais. Afinal, gasta-se muito tempo e esforço compreendendo elementos de um mesmo caso. Em consequência, tem-se um aprofundamento da compreensão de um objeto de pesquisa (MAHONEY e GOERTZ, 2006).

Em ambas as tradições, o perigo do viés é sempre presente. $E$ havendo viés na pesquisa, salvo em algumas condições, a inferência será influenciada por essa distorção. Ressalta-se que a própria combinação de métodos e técnicas das duas tradições podem potencializar o viés, ou minimizá-lo. Portanto, não é a escolha da tradição, ou a união delas, que irá resolver os problemas de inferência, mas a boa execução da pesquisa.

Como mencionado no princípio desta secção, a importância de uma boa inferência está associada à necessidade de melhorar a teoria, e a potencialidade de contribuir para a evolução da própria ciência política. Em face disso, para que o campo se desenvolva de maneira saudável, é necessário que as inferências sejam feitas com base em dados realmente confiáveis e que os próprios métodos sejam inovadores, para que inferências sejam realizadas a partir de outras perspectivas. Nesse sentido, o diálogo entre as tradições metodológicas, e a contribuição de King, Keohane e Verba (1994) e demais obras nesse debate, semeia o terreno para o melhor desenvolvimento da ciência política. 


\section{A CAUSALIDADE}

A causalidade é uma relação entre duas ou mais variáveis, onde uma das variáveis, a dependente, é explicada pela(s) outra(s). Porém, não há, ainda, um método que permita estabelecer de forma objetiva uma relação causal. O ferramental quantitativo permite estabelecer uma relação e testar sua consistência estatística. Porém, é a teoria e as observações empíricas que permitirão a inferência de uma causalidade nessa relação. Assim, pode-se concluir que há uma intima conexão deste elemento com a secção anterior, que tratou da inferência. Originalmente, a causalidade é um objetivo tradicionalmente perseguido pelo campo quantitativo das ciências sociais.

É nítido que nem toda inferência estabelece uma relação de causalidade, ou mesmo consegue fundamentar uma correlação. Porém, determinar que um fenômeno é causado por outro, ou por um conjunto de outros elementos, tem um poder explicativo da realidade interessante para a pesquisa científica. Nesse sentido, por mais que a tradição qualitativa tenha seus méritos e seu poder explicativo, é na teoria estatística mainstream que se encontra o ferramental mais apropriado para fundamentar a inferência de uma correlação. Em outras palavras, uma regressão parece ser, até o momento, o meio mais consistente para estabelecer o quão provável de uma correlação ser verdadeira e afastar outras possíveis relações. Note-se ainda que, ante a existência dessas relações, a pesquisa qualitativa ganha um enorme destaque, permitindo que o resultado "frio" de uma regressão seja melhor fundamentado, atribuindo valor subjetivo às variáveis e à própria relação. Partindo de uma regressão bem feita, e com outros cuidados, como uma construção teórica bem feita, é possível apresentar uma relação de causalidade aceitável e fundamentada.

Em referência a acepção destacada por Kirchbaum (2013), pesquisas qualitativas tradicionalmente seriam aquelas que teriam "interesses de pesquisa tipicamente subjetivistas", enquanto os quantitativistas, ainda tradicionalmente, atendem às demandas da corrente positivista, centrando suas pesquisas em relações causais. Entretanto, o próprio autor ressalta o papel que os qualitativistas potencialmente têm no estabelecimento e interpretação de relações causais.

A conhecida "separação de trabalhos" (KIRSCHBAUM, 2013), entre as tradições metodológicas precisa ser revista e discutida com frequência. E, é partindo dessa perspectiva, que se discute o papel da tradição qualitativa no estabelecimento de relações causais. Esse papel pode ir desde a utilização de ferramentas como QCA (Qualitative Comparative Analysis), onde dados qualitativos são trabalhados da mesma forma que os dados quantitativos, até a associação de métodos das duas tradições, com o objetivo de utilizar as informações subjetivas obtidas através de inferências qualitativas para interpretar e dar significado aos resultados obviamente numéricos da ferramenta quantitativa.

A tradição qualitativa tem um poder reconhecido pelas principais referências da metodologia nas ciências sociais (como o trio King, Keohane e Verba (1994), Brady e Collier (2004), entre outros) de atribuir significado aos números. Em outras palavras, o ferramental qualitativo, associado ao quantitativo, pode permitir a construção de teorias 
de maior alcance, e ir mais além, desafiando a teoria, e como consequência, melhorá-la.

No décimo capítulo da importante coletânea de Brady e Collier (2004), "Bridging the Quantitative-Qualitative Divide", de autoria de Sidney Tarrow, são apresentadas alguns mecanismos de como combinar as duas tradições em uma mesma pesquisa e quais as contribuições que cada uma delas pode dar ao trabalho, em função de como e que tipo de ferramentas de cada uma das tradições sejam aplicadas. No referido texto, o autor dá apenas algumas dicas do que pode ser feito em termos de aplicação das tradições metodológicas, não entrando em questões específicas de como, mas sim, das razões para fazer.

É necessário ressaltar apenas que essa associação de métodos, ou mesmo a utilização de métodos que permitam o estabelecimento de relações causais a partir de dados qualitativos (como faz o QCA) caminha no limiar da inovação e do risco. Ao passo que é possível contribuir com inovadores resultados ao campo de estudo, também se pode, sem o devido cuidado, acabar criando resultados pouco confiáveis, que induzam o pesquisador ao erro. Infelizmente, para os iniciantes na pesquisa científica, no caso de um método ainda não testado, é necessário muita reflexão e expor o máximo possível o método pretendido à discussão com os pares e acadêmicos mais experientes, para que seja possível confiar no método (KING, KEOHANE e VERBA, 1994).

\section{CONSIDERAÇÕES FINAIS}

Do ponto de vista deste trabalho, é nítido que as duas tradições têm suas contribuições à pesquisa científica. A própria ciência política tem muito a ganhar (de capacidade de inferência, de profundidade analítica, de inovação) se cessarem as disputas sobre quem tem primazia na ciência, e se surgirem cooperações e trabalhos que bebam das duas fontes (métodos mistos). Porém isto já foi levantado por vários trabalhos seminais, alguns citados neste texto, como o próprio texto de King, Keohane e Verba (1994), a coletânea que crítica esta primeira obra organizada por Brady e Collier (2004), e tantos outros.

O desenho de pesquisa possui um relevo fundamental. É o guia mestre do cientista social na busca da análise do seu objeto. No entanto, o pesquisador deve ser flexível ao ponto de saber reinventar o seu desenho, sempre respeitando as normas de inferência. Explica King, Keohane e Verba (1994) que é muito comum que um excelente desenho de pesquisa não saia como previsto quando se colhem as primeiras observações. Mas não é, necessariamente, a teoria que está equivocada, sim os dados que podem não estar apropriados para responder as perguntas levantadas no princípio (assim como, é possível que o método bem executado prove que a teoria estava equivocada, ou não explicava toda a realidade que esperava). É por isso que o desenho deve ser muito bem pensado, de forma a se evitar ao máximo a perda de tempo (especialmente se comprovar um equívoco da teoria. Pois esse resultado fará a pesquisa passar por um escrutínio ainda maior). 
Esta pergunta de pesquisa, que traduz o problema a ser estudado, deve ser o princípio do desenho. Com uma pergunta bem feita, as próximas etapas da pesquisa vão se abrindo de forma mais clara. E uma questão fundamental nessa etapa, para King, Keohane e Verba (1994), é que o problema se ocupe de um assunto relevante do mundo real e dialogue com a bibliografia acadêmica. Deve-se buscar encontrar que perguntas de interesse para a pesquisa já foram respondidas, e de que forma se pode suscitar e polir a pergunta para que pareça possível contestá-la com as ferramentas disponíveis. Assim, o problema e a pergunta de pesquisa poderão dar o suporte para delinear o meIhor método a ser utilizado, seja ele qualitativo ou quantitativo (ou até mesmo, ambos).

Sobre as inferências, o papel de cada uma das tradições científicas é claro. A pesquisa quanti tem uma capacidade de estabelecer parâmetros estatísticos e conceder às inferências uma áurea de formalidade necessária para a sobriedade dos estudos. A pesquisa quali fornece subsídios para que esta inferência seja menos "fria", e consistente com a realidade estudada.

É preciso ter em mente que por mais sólidos e diversos que sejam os métodos, as inferências sempre serão conclusões e interpretações subjetivas da realidade extraídas da análise dos dados, sejam eles quantitativos ou qualitativos. É preciso que os autores das ciências sociais mantenham um grau de modéstia em relação à sua capacidade de interpretar a realidade, por mais sofisticados que sejam seus métodos, por maior diversidade de ferramentas empregadas e por mais sólida que seja a sua teoria. Trata-se sempre de uma aproximação da realidade, formulação teóricas ou contribuições à teoria já existente que terão, no máximo, médio alcance.

Em relação à causalidade, podemos concluir que, apesar de ser um objetivo perseguido originalmente pela tradição quantitativa, a pesquisa qualitativa tem muito a contribuir no estabelecimento de novas relações causais. Porém, é na aproximação dessas tradições que está o ponto crítico para a evolução da ciência, onde se pode estabelecer relações causais mais inovadoras e com maior consistência, tendo em vista que a causalidade é uma inferência extraída de uma testada relação, submetida à interpretação do pesquisador, à luz da teoria.

Ao estabelecer que existe uma relação entre duas variáveis, exclui-se outras possíveis explicações, e constrói-se uma explicação teórica para tal relação. Nem sempre é possível observar qual variável surgiu primeiro. Esta precedência permitiria dizer com certeza que quais seriam as variáveis explicativas, e qual seria a variável dependente.

O surgimento de estudos experimentais, ou de quase-experimentos, lança a possibilidade de que essas relações causais possam ser testadas, e comprovadas. Porém, até o momento, esses estudos comprovam a relação causal em um, e apenas um contexto. A projeção dos resultados para interpretar outros casos demanda novos estudos. Qualquer inferência que pretenda projetar os resultados para outros contextos será apenas uma previsão. 


\section{REFERÊNCIAS}

BARTELS, L. M. (2004). Some Unfulfilled Promises of Quantitative Imperialism. In: BRADY, Henry E.; COLLIER, David. Rethinking Social Inquiry: Diverse Tools, Shared Standards. New York.

BORGES, A. (2007). Desenvolvendo Argumentos Teóricos a Partir de Estudos de Caso: o Debate Recente em Torno da Pesquisa Histórico-Comparativa. BIB - Revista Brasileira de Informação Bibliográfica em Ciências Sociais, p. 45-59.

BRADY, H. E.; COLLIER, D. (2004). Rethinking Social Inquiry: Diverse Tools, Shared Standards. New York.

BRADY, H. E.; COLLIER, D.; SEAWRIGHT, J. (2004). Refocusing the Discussion of Methodology. In: BRADY, H. E.; COLLIER, D. Rethinking Social Inquiry: Diverse Tools, Shared Standards. New York.

BRADY, H. E. (2004). Doing Good and Doing Better: How Far Does the Quantitative Template Get Us? In: BRADY, H. E.; COLLIER, D. Rethinking Social Inquiry: Diverse Tools, Shared Standards. New York.

FILHO, D. B. F., et al. (2012). Levando Gary King a sério: desenhos de pesquisa em ciência política. Revista Eletrônica de Ciência Política, vol. 3, n 1-2, p. 86-117.

KING, G.; KEOHANE, R.; VERBA, S. (1994). Designing Social Inquiry: Scientific Inference in Qualitative Research. New Jersey. Princeton University Press.

KIRSCHBAUM, C. (2013). Decisões sobre pesquisas Quali e Quanti sob a perspectiva de mecanismos causais. Revista Brasileira de Ciências Sociais, vol. 28, nº 82, p. 179-193.

LANDMAN, T. (2011). Política Comparada. Una Introdución a su objeto y métodos de investigación. Madrid: Alianza Editorial.

LEVY, J. S. (2007). Qualitative Methods and Cross-Method Dialogue in Political Science. Comparative Political Studies, vol. 40, p. $196-214$

PÉREZ-LIÑÁN, A. (2010). El método comparativo y el análisis de configuraciones causales. Revista Latinoamericana de Política Comparada, vol. 3, p. 125-148.

MAHONEY, J. (2007). Qualitative Methodology and Comparative Politics. Comparative Political Studies, $n^{\circ} 40$, p. 122-144.

MAHONEY, J.; GOERTZ, G. (2006). A Tale of Two Cultures: Contrasting Quantitative and Qualitative Research. Political Analysis, $n^{\circ} 14$, p. 227-249.

REZENDE, F. da C. (2011). A "Nova Metodologia Qualitativa" e as Condições Essenciais de Demarcação entre Desenhos de Pesquisa na Ciência Política Comparada. Revista 
Política Hoje, vol. 20, n 1, p. 218-252.

ROGOWSKY, R. (2004). How Inference in the Social (but Not the Physical) Sciences Neglects Theoretical Anomaly. In: BRADY, H. E.; COLLIER, D. Rethinking Social Inquiry: Diverse Tools, Shared Standards. New York.

\title{
SOBRE OS AUTORES
}

Rodrigo Leite é doutorando em Ciência Política na Universidade Federal de Pernambuco, mestre em Direito pela Universidade de Lisboa e Professor de Direito da Universidade Federal Rural do Semiárido (UFERSA).

E-mail: rodrigoleite@ufersa.edu.br.

Gustavo de Andrade Rocha é doutorando em Ciência Política na Universidade Federal de Pernambuco, mestrado em Economia e Bacharelado em Relações Internacionais. Professor de Relações Internacionais e Ciência Política no Centro Universitário Tabosa de Almeida e pesquisador do Instituto de Estudos da Ásia (UFPE) e do Grupo de Estudos e Pesquisa em Ásia e Pacífico (UEPB).

E-mail: gustavo_atos@hotmail.com

\begin{abstract}
This paper aims to address three key issues in the context of research in political science: the research design, inference and causality. To do so, it will address these issues by establishing the parallels of qualitative and quantitative approaches. As a result, stabilish that despite the quantitative method has its scientific nature most accepted, face to the use of statistical tools, qualitative methods also have their own elements and techniques that can contribute to the development of causal inferences. Allied to this factor, the research that use both methods for hypothesis testing can also be a great ally of political science and the new studies corroborate the area trying to mitigate the old dichotomy between quantitative and qualitative techniques.
\end{abstract}

Keywords: Political Science; Methodology; Qualitative; Quantitative.

Resumen: El presente ensayo pretende abordar tres cuestiones fundamentales en el ámbito de la investigación en ciencia política: el diseño de investigación, la inferencia y la causalidad. Para ello, discurrirá estas cuestiones estableciendo los paralelos de cada uno entre los enfoques cualitativo y cuantitativo. Como resultado, establecerá que mientras el método cuantitativo tener su cientificidad más aceptada, ante el uso de técnicas estadísticas, los métodos cualitativos poseen también elementos y técnicas propias que pueden contribuir a la elaboración de inferencias causales. Aliado 